\title{
POSITION PAPER: Reprocessing of Critical Foot Care Devices
}

\author{
This position statement was developed by IPAC Canada's Reprocessing Interest Group: \\ Principal authors: Clare Barry, BN, MSc, CIC; ${ }^{1}$ Tina Stacey-Works, MLT, CIC; ${ }^{2}$ Merlee Steele-Rodway, RN, CERT; ${ }^{3}$ \\ Nicole Kenny, BSc Assoc Chem; ${ }^{1}$ Donna Perron, RN, CIC; ${ }^{4}$ Mandy Deeves, RN, MPH, CIC; ${ }^{5}$ \\ Janet Bristeir, RN; ${ }^{6}$ Romy Burgess Burfitt, RN, RP;7 Andrea Skeoch, RN; ${ }^{8}$ Anne Augustin, MLT, CIC ${ }^{9}$ \\ Affiliations: $\quad \quad{ }^{1}$ IPAC Canada - Greater Toronto Area region, ON, Canada \\ ${ }^{2}$ Halton Healthcare, Oakville Trafalgar Memorial Hospital; \\ IPAC Canada - Central South Ontario region, ON, Canada \\ ${ }^{3}$ Canadian Association of Medical Device Reprocessing; \\ IPAC Canada - Newfoundland and Labrador region, NL, Canada \\ ${ }^{4}$ Public Health Ontario; IPAC Canada - Ottawa region, ON, Canada \\ ${ }^{5}$ Public Health Ontario; IPAC Canada - Simcoe Muskoka region, ON, Canada \\ ${ }^{6}$ Vancouver General Hospital; IPAC Canada - British Columbia region, BC, Canada \\ ${ }^{7}$ College of Health Studies, Brampton, ON; IPAC Canada \\ 8IPAC Canada - Southern Alberta region, AB, Canada \\ ${ }^{9}$ Public Health Ontario; IPAC Canada - Peel and Neighbouring region, ON, Canada \\ Original date: \\ October 2018 \\ Revised: \\ July 2019
}

\section{BACKGROUND}

Foot care devices have been associated with healthcare-associated infections and outbreaks [1-6]. The goal of this document is to provide infection prevention and control recommendations for the management of critical foot care equipment and/or devices. This will include cleaning, disinfection, sterilization, transportation, and storage.

\section{POSITION STATEMENT}

Clients expect and require safe care regardless of where the procedure is performed. Therefore, each client interaction requires a sterile set of foot care equipment/devices.

1. Reusable foot care equipment/devices are considered critical devices [7-13].

2. All healthcare providers:

- Shall have a sufficient number of foot care equipment/ devices/kits to ensure sterile equipment, either single-use or properly reprocessed, for each individual client treatment.

- Are responsible to ensure that the client is not placed at risk of infection when reusing any foot care equipment/devices during the provision of care.

3. Reprocessing of reusable foot care equipment/devices shall meet the manufacturer's instructions for use (MIFU) and current national guidelines such as those of the Canadian Standards Association (CSA) and the Public Health Agency of Canada (PHAC/Health Canada), as well as provincial standards $[9,13]$.

- Reusable equipment/devices are sold with MIFU, including for proper cleaning and sterilization, and shall not be purchased, used, or reprocessed without these. Determine reprocessing methods in advance of purchase. Single-use medical equipment/devices do not have such instructions and shall not be reprocessed [7, 8, 13, 14].

- Critical medical equipment/devices shall be sterile for use and MIFU for parameters for sterilization shall be followed.

- If the process used for reprocessing cannot meet the current standards, single-use disposable items shall be used and discarded after use.

- Nail clippers should be deemed single-use if no MIFU are available or if the MIFU do not meet recognized standards.

4. Medical equipment/devices used to provide foot care should be used according to the MIFU (i.e., for the intended purpose and following instructions for use, as per the manufacturer) and designed for use on humans, specifically feet (e.g., rotary sanding device and accessories). Medical equipment/devices that are designated as Class II or higher require a medical device licence. Health Canada's Medical Devices Active Licence Listing (MDALL)/Medical Devices Establishment Licence Listing (MDEL) are resources to verify if the equipment or establishment is approved in Canada.

5. Options to achieve a sterile set of foot care equipment/devices for each client interaction include:

Option 1: Use single-use sterile disposable equipment/ devices and discard appropriately after use [10, 11].

Option 2: Multi-client reusable foot care equipment/devices reprocessed using the contracted services of a centralized Medical Device Reprocessing Department (MDRD). The contracted MDRD meets CSA standards and has qualified technicians to perform the reprocessing (cleaning and steam sterilization) [10]. 
- This equipment requires thorough decontamination (cleaning and disinfection), packaging, and steam sterilization between each client use and shall follow CSA standards for storage of sterile supplies to ensure they maintain sterility.

- Best practices for transportation and storage of soiled and reprocessed equipment/devices shall be incorporated and meet current CSA standards.

- There shall be a robust process for recall of reprocessed equipment/devices in the event of reprocessing failure. Load records, proper labelling, and chemical and biological indicators are required.

Option 3: The healthcare provider chooses to reprocess reusable equipment/devices themselves, with the following considerations incorporated into practice:

- Follow current pertinent CSA standards documents [13, 15] for reprocessing practices and purchasing and follow these, along with provincial reprocessing guidelines.

- The healthcare provider shall have written procedures based on current standards [13, 15].

- Education: "Personnel involved in all medical device reprocessing functions shall be prepared for the tasks that they are required to perform through formal education and training" [13], including, at minimum:

- Following national and provincial guidelines $[9,13]$.

- Education and competency related to all equipment/ devices used in the process; maintenance, quality testing, and monitoring of the sterilization process; packaging, storage, and transportation of reprocessed equipment/devices, including chemicals; and sterilization equipment.

- Training to a level required for the volume and complexity of the equipment $[7,8]$.

- Reprocess equipment following the MIFU for the device and the sterilizer.

- Ensure the MIFU for each piece of equipment meet recognized accepted standards for reprocessing.

- Steam sterilization is required for foot care instruments and the sterilizer requires a printout or electronic record for each cycle [13].

- Follow quality assurance recommendations, including monitoring and documentation of mechanical, chemical, and biological indicators [15].

- There shall be a robust process for recall of reprocessed equipment/devices in the event of reprocessing failure, including labelling of all packages with the sterilization date, load, sterilizer number, name of the medical device, and initials of the person packaging the device.

- Best practices for transportation and storage of soiled and reprocessed equipment/devices shall be incorporated. If using event-related sterility, a quality system is required with policies and procedures for the storage process.

- Incorporate a preventative maintenance schedule according to equipment MIFU, including maintenance procedures, cleaning frequency of autoclave and reprocessing area, and annual autoclave calibration by a certified technician.

- There shall be a procedure outlining actions to be taken if parameters of cleaning and sterilization are not met, including documentation of steps taken to remediate.

- The foot care provider shall follow occupational health and safety guidelines (e.g., Routine Practices and Additional Precautions, appropriate personal protective equipment, safe sharps management, hand hygiene, and the procedure for staff exposures that occur during reprocessing) [7].

Note: The use of liquid chemicals for sterilization of instruments is not recommended for critical equipment/devices that are used for sterile procedures due to the limitations in maintaining sterility to point of use [16]. "Devices cannot be wrapped or adequately contained during processing in a liquid chemical sterilant to maintain sterility following processing and during storage" [14].

Unacceptable methods of sterilization include ImmediateUse Steam Sterilization, formerly referred to as flash sterilization; glass bead sterilizer; microwave oven; boiling; Chemiclave; steam sterilizers without printouts or electronic recording; dry heat (in this setting); and ultraviolet irradiation [8].

\section{STAKEHOLDERS}

Healthcare providers performing foot care in any healthcare setting, which includes but is not limited to care provided in private homes, clinics, and healthcare settings. (See "healthcare setting" definition.)

\section{GLOSSARY}

As per the Canadian Standard Association:

"SHALL" is used to express a requirement, i.e., a provision that the user is obliged to satisfy in order to comply with the standard;

"SHOULD" is used to express a recommendation or that which is advised but not required; and

"MAY" is used to express an option or that which is permissible within the limits of the standard, an advisory or optional statement.

Class II equipment/devices: All invasive devices that penetrate the body through a body orifice or that come into contact with the surface of the eye are classified as Class II. See Classification Rules for Medical Devices (https://health-products.canada.ca/ mdall-limh/index-eng.jsp).

Client: Includes patient, client, and resident.

Critical medical equipment/devices: Medical equipment/ devices that enter sterile tissues, including the vascular system (e.g., biopsy forceps, foot care equipment, dental hand pieces, etc.). Critical medical equipment/devices present a high risk of infection if the equipment/device is contaminated with any microorganism, including bacterial spores. Reprocessing critical equipment/devices involves meticulous cleaning followed by sterilization [8]. 
Foot care: Routine care includes a clinical assessment of the feet, education for the client, and care that only involves the epidermal layer of the skin or nails. Routine care may include the filing of corns or calluses, the filing or trimming of nails, and skin care. Invasive foot care includes contact with non-intact skin and surgical interventions with entry into or contact with the epidermal, dermal, deep fascial, and osseous structures. Foot care is performed by healthcare providers (e.g., chiropodists, podiatrists, nurses, advanced independent practice nurses) within their defined scope of practice.

Healthcare provider: Any healthcare professional delivering foot care service to a client as well as those performing reprocessing duties.

Healthcare setting: Any location where healthcare is provided, including home healthcare, offices of other health professionals, outpatient clinics, emergency care, hospitals, complex continuing care, rehabilitation hospitals, long-term care homes, mental health facilities, community health centres and clinics, physician offices, dental offices, independent health facilities, out-ofhospital premises, and public health clinics.

Manufacturer's instructions for use (MIFU): The written instructions for use provided by the manufacturer or distributor of a product that contain the necessary information for the safe and effective use of the product [13]. The manufacturer's validated instructions for use must be followed to ensure proper and safe use of a product regardless of other guidelines.

\section{Medical Devices Licences:}

Medical Devices Active Licence Listing (MDALL): Reference tool for licensed medical devices in Canada by Health Canada, accessible at https://health-products.canada.ca/mdall-limh/indexeng.jsp.

Medical Devices Establishment Licence Listing (MDEL): List of holders of an active medical devices licence by Health Canada, available at https://health-products.canada.ca/mdel-leim/indexeng.jsp.

Single-use/disposable: A term given to medical equipment/ devices designated by the manufacturer for single-use only. Single-use equipment/devices must not be reprocessed.

Sterilization: The level of reprocessing required when processing critical medical equipment/devices. Sterilization results in the destruction of all forms of microbial life [13], including bacteria, viruses, spores, and fungi. Equipment/devices must be cleaned thoroughly before effective sterilization can take place.

\section{REFERENCES}

1. Centers for Disease Control and Prevention (CDC). (2018, September). Healthcare-associated hepatitis B and C outbreaks ( $\geq 2$ cases) reported to Centers for Disease Control and Prevention (CDC) 2008-2017. Retrieved from https://www. cdc.gov/hepatitis/outbreaks/pdfs/HealthcarelnvestigationTable.pdf

2. Wise, M. E., Marquez, P., Sharapov, U., Hathaway, S., Katz, K., Tolan, S., Beaton, A., Drobeniuc, J., Khudyakov, Y., Hu, D. J., Perz, J., Thompson, N. D., \& Bancroft, E. (2012). Outbreak of acute hepatitis B virus infections associated with podiatric care at a long-term care facility. American Journal of Infection Control, 40(1), 8-21. doi: 10.1016/j.ajic.2011.04.331

3. Wenger, J. D., Spika, J. S., Smithwick, R. W., Pryor, V., Dodson, D. W., Carden, G. A., \& Klontz, K. C. (1990). Outbreak of Mycobacterium chelonae infection associated with use of jet injectors. JAMA, 264(3), 373-376. Retrieved from https://www.ncbi.nlm.nih.gov/pubmed/2362334

4. Rutala, W. A., Weber, D. J., \& Thomann, C. A. (1987). Outbreak of wound infections following outpatient podiatric surgery due to contaminated bone drills. Foot Ankle, 7(6), 350-354. Retrieved from https://www.ncbi.nlm.nih.gov/ pubmed/3301597

5. Wise, M. E., Bancroft, E., Clement, E. J., Hathaway, S., High, P., Kim, M., Lutterloh, E., Perz, J. F., Sehulster, L. M., Tyson, C., White-Comstock, M. B., \& Montana, B. (2015). Infection prevention and control in the podiatric medical setting: Challenges to providing consistently safe care. Journal of the American Podiatric Medical Association, 105(3), 264-272. doi: https://doi.org/10.7547/0003-0538-105.3.264

6. Hathaway, S., Marquez, P., \& Bancroft, E. (2008). Hepatitis $B$ outbreak in a skilled nursing facility. In Acute Communicable Disease Control Program, Special studies report 2008 (pp. 43-46). Retrieved from http://publichealth.lacounty.gov/ wwwfiles/ph/dcp/acd/2008SpecialStudies.pdf

7. Ontario Agency for Health Protection and Promotion (Public Health Ontario). (2015, April). Infection prevention and control for clinical office practice (1st rev.). Retrieved from www. publichealthontario.ca/en/eRepository/IPAC_Clinical_Office Practice_2013.pdf

8. Ontario Agency for Health Protection and Promotion (Public Health Ontario). (2013, May). Best practices for cleaning, disinfection and sterilization of medical equipment/devices in all health care settings (3rd ed). Retrieved from http://www. publichealthontario.ca/en/eRepository/PIDAC_Cleaning_Disinfection_and_Sterilization_2013.pdf

9. Public Health Agency of Canada. (1997, December). Infection control guidelines: Foot care by health care providers. Canada Communicable Disease Report, 23S8. Retrieved from http://publications.gc.ca/collections/collection_2016/ aspc-phac/HP3-1-23-S8-eng.pdf

10. Alberta Health Services. (2013, July). Infection prevention and control (IPC) best practice guidelines for foot care devices. Retrieved from https://www.albertahealthservices.ca/ ipc/hi-ipc-footcare-bpg.pdf

11. Winnipeg Regional Health Authority. (2013, October). Community infection prevention \& control manual: Nursing foot care infection prevention \& control management in community health services. Retrieved from http://www.wrha.mb.ca/ extranet/ipc/files/manuals/community/2.2.6.pdf

12. College of Podiatrists of Manitoba. (2007, November). Schedule B: Standards of practice. Standard 4: Infection control guidelines. Retrieved from http://www.copom.org/legislation/4_Practice_Standards_iv-Infection-Control-Guidelines.pdf 
13. Canadian Standards Association (CSA). (2018). CAN/CSAZ314-18 Canadian medical device reprocessing. Rexdale, ON: Canadian Standards Association.

14. Centers for Disease Control and Prevention (CDC). (2019, May). Guideline for disinfection and sterilization in healthcare facilities, 2008. Retrieved from https://www.cdc.gov/infectioncontrol/pdf/guidelines/disinfection-guidelines-H.pdf

15. IPAC Canada. (2014, January). Infection prevention and control audit for foot care. Audit Toolkit Version 2. Retrieved from https://ipac-canada.org/ipac-canada-products-2.php

16. Canadian Association of Foot Care Nurses (CAFCN). (2017). National competencies for advanced nursing foot care in Canada. Retrieved from https://cafcn.ca/wp-content/uploads/ CAFCN-National-Competencies-for-Advanced-Nursing-FootCare.pdf

\section{APPENDIX: FOOT CARE EQUIPMENT}

In the delivery of foot care services, equipment often intentionally or unintentionally comes into contact with blood, body fluids, or non-intact skin, requiring sterilization. Therefore, it is imperative to manage all equipment as if it has been contaminated. Soil is not always readily visible. Infection prevention and control best practices indicate there should be one reprocessing system for all equipment from any client.

Reprocessing of reusable foot care equipment/devices must meet manufacturer's instructions for use (MIFU) and current national guidelines such as those of the Canadian Standards Association (CSA) and the Public Health Agency of Canada (PHAC/Health Canada), as well as provincial standards $[9,13]$.

TABLE 1: Adapted from the Spaulding Classifications.

\begin{tabular}{|c|c|c|c|}
\hline Class & Use & $\begin{array}{c}\text { Minimum } \\
\text { Level of } \\
\text { Reprocessing }\end{array}$ & Examples \\
\hline Critical & $\begin{array}{l}\text { Equipment/ } \\
\text { devices } \\
\text { that enter } \\
\text { sterile body } \\
\text { site (e.g., } \\
\text { below the } \\
\text { epidermis), } \\
\text { including } \\
\text { the vascular } \\
\text { system. }\end{array}$ & $\begin{array}{l}\text { Thorough } \\
\text { cleaning } \\
\text { followed by } \\
\text { sterilization. }\end{array}$ & $\begin{array}{l}\text { - Scalpel handle } \\
\text { - Scissors } \\
\text { - Callus parer } \\
\text { - Halstead mosquito } \\
\text { forceps } \\
\text { - Probe } \\
\text { - Nail splitter } \\
\text { - Curette } \\
\text { - Nail elevator } \\
\text { - Debris evacuator } \\
\text { - Double-ended Black's } \\
\text { file } \\
\text { - Barrel nail nipper } \\
\text { - Diamond Deb file } \\
\text { - Single-ended } \\
\text { Black's file } \\
\text { - Stainless steel foot } \\
\text { paddle handle } \\
\text { Note: These are } \\
\text { examples and not an } \\
\text { inclusive list for foot care. }\end{array}$ \\
\hline
\end{tabular}

Single-use equipment/devices (these examples are not an inclusive list):

- Scalpel blades

- Callus parer blade

- Foot paddle sanding pad

- Monofilament

- Nail clipper (unless the MIFU state otherwise)

- Toenail nipper (unless the MIFU state otherwise)

- Ingrown nail nipper (unless the MIFU state otherwise)

- Nail files/emery board/orange stick

Management of burrs

- Burr/disk on rotary sanding tools - Rotary Sanding Tools: Equipment/devices used to provide foot care must be approved for medical use and designed for use on humans, specifically feet (e.g., rotary sanding device and accessories). If used, it should be purchased from an authorized medical manufacturer. The burr/disk (unless stated otherwise by the manufacturer) must be considered a single-use device and cannot be reprocessed.

- Burrs deemed reusable by the manufacturer may be reprocessed following the MIFU, and the MIFU must meet current national guidelines such as those of the CSA and PHAC/ Health Canada, as well as provincial standards $[9,13]$. 